See Article page 1142.

\section{Commentary: Can a small hole make such a big difference?}

\author{
Emile Bacha, MD
}

The study by Callahan and colleagues, ${ }^{1}$ based on prospectively enrolled but nonrandomized patients with atrioventricular septal defects (AVSDs), reminds us why the Congenital Heart Surgeons Society was created in the first place. This study can stand proudly in a line of other important studies that were based on the Congenital Heart Surgeons Society registry, on topics ranging from interrupted aortic arch to transposition of the great arteries. ${ }^{2}$ The present study comprises 581 patients (a large " $n$ " when dealing with pediatric cardiac studies) who underwent AVSD repair at 31 institutions. Two groups of patients were created: If the surgeon mentioned in the operative report that a fenestration was left behind intentionally (as an "intention-totreat" a potential postoperative risk), then the patient was counted as being part of the fenestrated group, irrespective of whether the discharge echocardiogram detected a fenestration or not. Conversely, if no fenestration was placed during surgery but an unintentional residual atrial shunt was detected on the discharge echo, that patient was still counted in the nonfenestration group, as there was no intention-to-treat.

Before I get back to the issue of intention-to-treat, let me just state at the outset disclose my biases. Generally speaking, I do believe in an intentional atrial fenestration placed for expected right-sided postoperative problems, such as the diastolic dysfunction that occurs in a postoperative patient with tetralogy of Fallot, or an older AVSD with

\footnotetext{
From the Division of Cardiac, Thoracic and Vascular Surgery, NewYork-Presbyterian/Columbia University Medical Center, Morgan Stanley Children's Hospital and Komansky Children's/Weill-Cornell, New York, NY.

Disclosures: The author reported no conflicts of interest.

The Journal policy requires editors and reviewers to disclose conflicts of interest and to decline handling or reviewing manuscripts for which they may have a conflict of interest. The editors and reviewers of this article have no conflicts of interest.

Received for publication Sept 7, 2021; revisions received Sept 7, 2021; accepted for publication Sept 8, 2021; available ahead of print Sept 14, 2021.

Address for reprints: Emile Bacha, MD, Division of Cardiac, Thoracic and Vascular Surgery, NewYork-Presbyterian/Columbia University Medical Center, Morgan Stanley Children's Hospital and Komansky Children's/Weill-Cornell, 3959 Broadway, New York, NY 10032 (E-mail: eb2709@cumc.columbia.edu).

J Thorac Cardiovasc Surg 2022;163:1153-4

$0022-5223 / \$ 36.00$

Copyright (c) 2021 by The American Association for Thoracic Surgery

https://doi.org/10.1016/j.jtcvs.2021.09.012
}

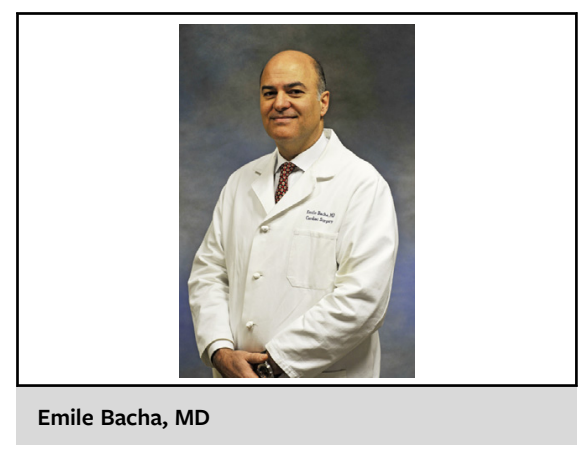

CENTRAL MESSAGE

This study looks at the intention of leaving an atrial fenestration in atrioventricular septal defect surgery. It shows a statistical association between intention to leave an ASD and worse survival.

proven pulmonary hypertension (typically older than 1 year and with trisomy 21), or a left ventricular-dominant AVSD (where one might argue a 1.5 ventricle repair with cavopulmonary shunt might be a better approach). I do not see any benefit at all in leaving an intentional fenestration in patients with left-sided problems such as in right ventricledominant AVSDs, nor do I leave intentional fenestrations in run-of-the-mill patients with AVSD. However, if I take the study's findings at face value, I would be wrong in some of my assumptions. The study found that both right and left dominant unbalanced groups had significantly lower 5-year survival. However, the biais (well acknowledged by the authors) that cannot be overcome in this study is whether the fenestrated group somehow represents a more complex group of patients. This is reflected in the greater incidence of unbalanced AVSD, previous pulmonary artery bands, aortopulmonary shunts, and coarctation/pulmonary artery band repairs as well as the significantly longer cardiopulmonary bypass times and more returns to cardiopulmonary bypass to address residual lesions in the fenestrated group.

It is important to remember that intention-to-treat is being analyzed, ${ }^{3}$ not the actual presence (and physiologic effect) of an atrial septal defect (ASD). Only $68 \%$ of patients in the fenestrated group had a fenestration detected on discharge echo, meaning one third of the "intended" atrial fenestrations had closed by the time of discharge! Conversely, $18 \%$ of patients in the nonfenestrated group 
were also found to have a fenestration at discharge. A better metric in my opinion would have been to use the discharge echocardiograms. Unfortunately, the survival data based on patency of an atrial fenestration on the discharge echocardiogram were not given for the entire cohort. However, for the fenestrated group, there were no survival differences based on patency of an ASD on the discharge echocardiogram.

As far as physiology is concerned, the authors point out that in the fenestrated group with an ASD seen on discharge echocardiogram, no significant differences in survival were seen based on if the atrial shunt was left-to-right compared with left-to-right and bidirectional. This finding does argue against a physiologic benefit for any residual ASD. In the end, I completely agree with the authors when they state that "routine practice of fenestration should be challenged." Also, the authors found that RV-dominant AVSD had the greatest risk of death overall and that a fenestration increased that risk even more. They argue that a residual fenestration in this setting produces unpredictable physiology, with which I also wholeheartedly agree.
Obviously, the correct way to get to the right answer would be a randomized clinical trial. Given the heterogeneity of AVSD anatomy and the low mortality after surgery, this would require thousands of patients and will not be done anytime soon. We are again confronted with the tyranny of small numbers combined with high anatomic heterogeneity that plague our specialty. In the end, what the study found is a significant statistical association of intention to leave an ASD with worse survival, and not a causality. That is worth remembering.

\section{References}

1. Callahan CP, Jegatheeswaran A, Barron DJ, Husain SA, Fuller S, Overman DM, et al. Association of atrial septal fenestration with outcomes after atrioventricular septal defect repair. J Thorac Cardiovasc Surg. 2022;163:1142-52.e6.

2. Devlin PJ, Jegatheeswaran A, Williams WG, Blackstone EH, DeCampli WM, Lambert LM, et al. Late survival and patient-perceived health status of the congenital heart surgeons' society dextro-transposition of the great arteries cohort. Ann Thorac Surg. 2019;108:1447-55.

3. Shriera I, Steele RJ, Verhagen E, Herbert R, Riddelle CA, Kaufman JS. Beyond intention to treat: what is the right question? Clin Trials. 2014;11:28-37.

\section{Commentary: Does atrioventricular septal defect atrial fenestration treat the child ... or the surgeon?}

\author{
Carl L. Backer, MD \\ Dr Connor Callahan, the Kirklin/Ashburn Fellow from the \\ Congenital Heart Surgeons' Society, has presented a pro- \\ vocative manuscript challenging the value of an
}

\footnotetext{
From the Section of Pediatric Cardiothoracic Surgery, UK HealthCare Kentucky Children's Hospital, Lexington, Ky; and Cardiothoracic Surgery, Heart Institute, Cincinnati Children's Hospital Medical Center, Cincinnati, Ohio.

Disclosures: The author reported no conflicts of interest.

The Journal policy requires editors and reviewers to disclose conflicts of interest and to decline handling or reviewing manuscripts for which they may have a conflict of interest. The editors and reviewers of this article have no conflicts of interest.

Received for publication July 22, 2021; revisions received July 22, 2021; accepted for publication July 23, 2021; available ahead of print July 28, 2021.

Address for reprints: Carl L. Backer, MD, UK HealthCare Kentucky Children's Hospital, 800 Rose St, C-259, Lexington, KY 40536-0293 (E-mail: Carl.Backer@uky edu).

J Thorac Cardiovasc Surg 2022;163:1154-5

$0022-5223 / \$ 36.00$

Copyright (c) 2021 by The American Association for Thoracic Surgery

https://doi.org/10.1016/j.jtcvs.2021.07.042
}

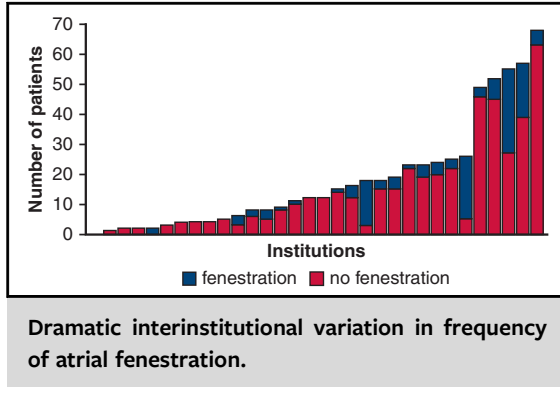

CENTRAL MESSAGE

In a Congenital Heart Surgeons'

Society review of 581 patients

undergoing atrioventricular

septal defect repair the use of an

intentional atrial fenestration was

associated with an increased

mortality risk.

intentionally created atrial fenestration in children undergoing biventricular repair of atrioventricular septal defect (AVSD). ${ }^{1}$ This is a comprehensive review of 581 patients enrolled from 32 Congenital Heart Surgeons' Society 